Journal of

Accident and

Emergency

Medicine 1995

$12,147-148$

\title{
Foreign body detected by patients using metal detectors
}

\author{
G.E.B.GIDDINS
}

The Royal National Orthopaedic Hospital, Brockley Hill, Stanmore, Middlesex HA7 4LP

\section{SUMMARY}

A positive response from a metal detector when run over an area of the body is a strong positive indicator of the presence of a metallic object. If there is a possibility of a buried metallic foreign body this positive finding should not be ignored.

Key words: foreign body, metal detector, radiograph.

\section{INTRODUCTION}

The cases of two patients are reported where metallic foreign bodies (FBs) were detected by patients using metal detectors. In the second patient the significance of this was not initially appreciated.

\section{Case one}

A 24-year-old man presented to the accident and emergency (A\&E) department of a hospital with a painful left forefoot having trodden on a sharp object 2 days previously. The pain had become worse and when he ran his metal detector over the area it registered, which did not occur with the right side. On examination he had a small puncture mark under the second metatarsal head. This was tender but not inflamed. A radiograph revealed a $2-\mathrm{cm}$ long metal dense FB. Under lignocaine local anaesthesia a shard of metal was removed.

\section{Case two}

A 30-year-old man presented to the A\&E department with a painful medial base of the right great toe having trodden on a needle that had broken. He had run a metal detector over the area and it had

Correspondence:

G.E.B. Giddins, Orthopaedic Senior Registrar, Flat 2, 2 Inverness Gardens, London W8 4RN, UK responded. He was examined and found to have a localized area of moderate tenderness with no inflammation on the medial side of the right first metatarsophalangeal joint. It was not considered that there was a retained FB and probing of the area

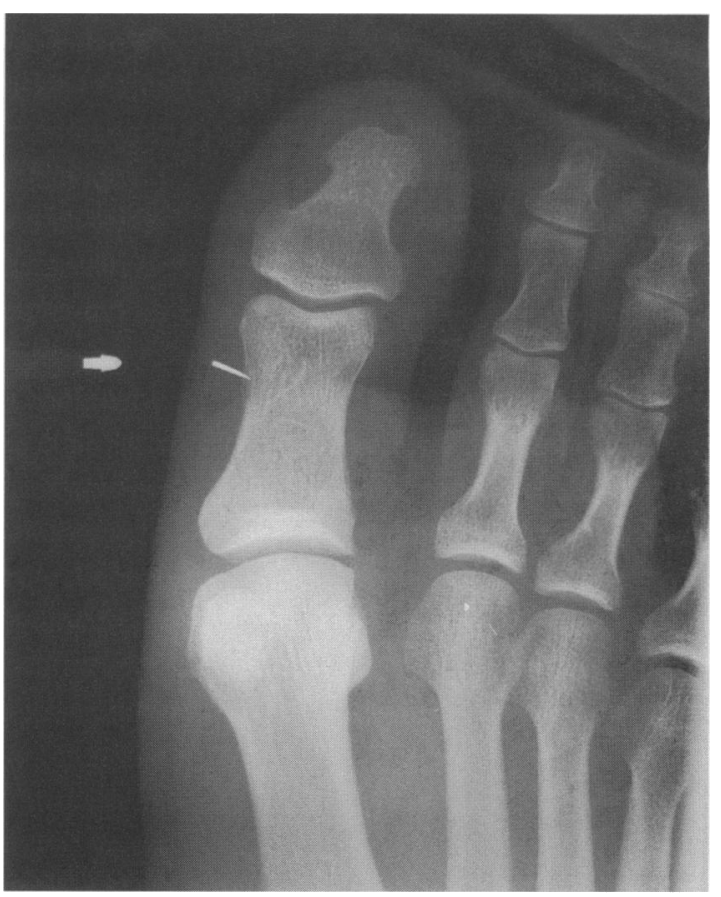

Fig. 1. A plain anteroposterior radiograph of the injured great toe in Case 2.

did not reveal an FB. He was discharged without a radiograph.

The patient re-presented 3 days later with a continuing positive response to the metal detector. The area was still tender but not inflamed. A radiograph was performed and revealed a $1-\mathrm{cm}$ metal dense FB. This was also explored under local anaesthesia and the broken end of the needle was removed.

\section{DISCUSSION}

Metal detectors, which were very much in fashion in the 1970s, are still widely used by both professional and amateur sleuths. Their specificity for metal is very high as is their sensitivity. They do not register simply by contact with the human body. A positive response from a metal detector is therefore path-

(C) 1995 Blackwell Science Ltd 
ognomonic of some intrabody metal provided the machine is not faulty. Therefore, a patient complaining of retained metal at a site which registers with a metal detector, as in Case 2, should not be ignored.

Metal detectors have previously been reported as being clinically useful but never in this context. ${ }^{1} 4$ They are useful adjuncts to diagnosis but are unlikely to replace radiographs as a cheaper means of detection owing to the problems of litigation and evidence.

\section{ACKNOWLEDGEMENTS}

I gratefully acknowledge the assistance given by Professor G. Bentley in the preparation of this manuscript and the permission to report upon his patients.

\section{REFERENCES}

1. Leicester R.J. \& Williams C.B. (1981) Use of metal detectors for localisation during fibre sigmoidoscopy or limited colonoscopy. Lancet 2, 232.

2. Lewis S.R. (1980) New use of a metal detector (letter). Pediatrics 65, 680-681.

3. Wetli C.V. (1979) Application of the Tri-ess mini metal detector to forensic autopsies (or to find the elusive projectile). Journal of Forensic Science 24, 656-659.

4. Wolter J.R. \& Wolter K.H. (1974) A simple and inexpensive metal detector for magnetic and non-magnetic foreign bodies. Transactions of the American Opthalmological Society 72, 363-367. 